\title{
PREDICTING SUITABLE DISTRIBUTION FOR AN ENDEMIC, RARE AND THREATENED SPECIES (GREY-SHANKED DOUC LANGUR, PYGATHRIX CINEREA NADLER, 1997) USING MAXENT MODEL
}

\author{
Tran, V. D. $.^{{ }^{*}}-$ Vu, T. T. ${ }^{1}-$ Tran, Q. B. ${ }^{2}-$ NGUYEN, T. H. $^{3}-$ TA, T. N. ${ }^{1}-$ HA, T. M. ${ }^{4}-$ NGUYEN, H. V. \\ ${ }^{1}$ Department of Wildlife, Faculty of Forest Resource and Environment Management, Vietnam \\ National University of Forestry \\ Xuan Mai, Chuong My, Ha Noi, Vietnam \\ ${ }^{2}$ Department of Environment Management, Faculty of Forest Resource and Environment \\ Management, Vietnam National University of Forestry, \\ Xuan Mai, Chuong My, Ha Noi, Vietnam \\ ${ }^{3}$ Faculty of Forest Science and Forest Ecology, Georg-August-Universität \\ Göttingen, Germany \\ ${ }^{4}$ Vietnamese Academy of Forest Science \\ Duc Thang, Bac Tu Liem, Ha Noi, Vietnam \\ ${ }^{5}$ Institute for Forest Ecology and Environment, Vietnam Forestry University \\ Xuan Mai, Chuong My, Hanoi, Vietnam \\ *Corresponding author \\ e-mail: dungtv@vfu.edu.vn; phone: +84-964-500-491 \\ (Received $4^{\text {th }}$ Oct 2017; accepted $5^{\text {th }}$ Feb 2018)
}

\begin{abstract}
Species distributional data has very important roles in management and conservation of wildlife, especially for rare species. In this study, we used the MaxEnt model to predict the potential distribution of the grey-shanked douc langur (Pygathrix cinerea Nadler, 1997) which is endemic to Vietnam and listed as one of the most endangered primate species in the world. We collected 158 independent localities and 16 environmental variables from different sources were used for analysis. The projection habitat suitability shows that the suitable areas are approximately from $14^{\circ} \mathrm{N}-16^{\circ} \mathrm{N}$. The precipitation of driest month (bio14) had the highest percentage contribution to the model output with $27.7 \%$. The total suitable area is $16,680.52 \mathrm{~km}^{2}$. The areas of high and very high suitability account for $19 \%$, and $2 \%$ respectively. The potential distribution area of the species is not much found in the existing protected area. Priorities for conservation and survey efforts should be given to the forested areas in Quang Ngai (Ba To district), Kon Tum (Kon Plong district), Binh Dinh (An Lao district), Gia Lai (K 'Bang district) and Quang Nam provinces. Conservation efforts should also be prioritized for areas beyond the boundary of protected areas, especially for areas that have been proposed as biodiversity corridors.
\end{abstract}

Keywords: douc langur, ecological niche modelling, maximum entropy, species distribution models, suitable habitat

\section{Introduction}

Lacking species distributional data has caused many difficulties in management and conservation of wildlife (Nazeri et al., 2012), especially rare species. Understanding the most basic requirements of living habitats and distribution of each species is a top priority for conservation programs and action plans. Species distribution modelling using an ecological niche model is an instrument that can be used to help us understand 
more about the distribution of species (Phillips et al., 2006; Nazeri et al., 2012). However, modelling the potential distribution or suitable habitat of a species requires a wide variety of complex data coming from environmental studies, natural resources studies, biodiversity assessment and detailed studies of species (Franklin and Miller, 2009; Sarma et al., 2015).

Ecological Niche Modelings (ENMs) is a method using occurrence data of species associated with environmental data, thereby creating models generate geographic areas which match with the ecological requirements of that species. ENMs is often used for the following purposes: (1) assessing/ estimating suitable habitat for species; (2) assessing changes in species distribution over time based on scenarios of changes in environmental conditions; (3) assessing ecological niches or ecological requirements of species (Warren and Seifert, 2011). The accuracy of the predicted results depends on a number of factors such as the complexity and accuracy of the models, the environmental data layers, and the species distribution data (Raxworthy et al., 2007). The study area is divided into different grid cells (pixel). Variables are used to generate a value of the environment at each grid cells, and algorithms are used to identify the degree of suitable or inappropriate of grid cells for the species (Raxworthy et al., 2007; Hirzel et al., 2002).

Grey-shanked douc langur (GSDL; Fig. 1) (Pygathrix cinerea Nadler, 1997) is one of three species in the genus Pygathrix that were recorded in Vietnam. P. cinerea was first described as a subspecies of $P$. nemaeus (Nadler, 1997). However, later genetic work suggested the divergence at the species level (Roos and Nadler, 2001). The current GSDL's populations are found in fragmented habitat in Central Vietnam, between $13^{\circ} 30^{\prime} \mathrm{N}$ and $16^{\circ} \mathrm{N}$. It has been recorded in five provinces: Quang Nam, Quang Ngai, Kon Tum, Gia Lai and Binh Dinh of Vietnam (Ha, 2000; 2004; Nadler et al., 2003; Nguyen et al., 2010; Nadler and Brockman, 2014). Most recently, the population of $P$. cinerea was estimated to be 600-700 individuals (Nadler, 2010). Hunting and habitat loss are serious threats to the population of the P. cinerea (Vu et al., 2008; Nguyen et al., 2012).

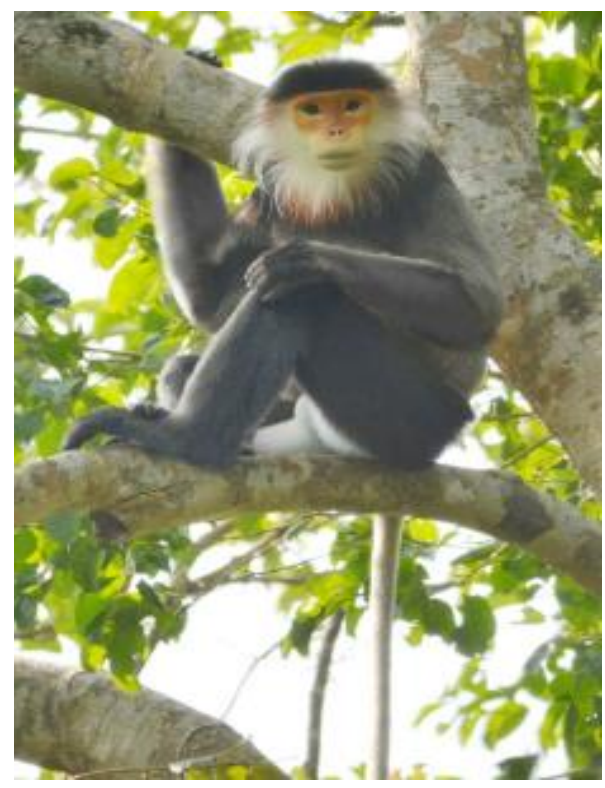

Figure 1. Grey-shanked douc langur (Pygathrix cinerea). (Source: Kon Ka Kinh National Park) 
GSDL is listed as "Critically Endangered" in the Vietnam Red Data Book (Ministry of Science and Technology and Vietnam Academy of Science and Technology, 2007) and the IUCN Red List of Threatened Species since 2008 (Vu et al., 2008) because the population was declining at over $80 \%$ in the entire distribution range due to several threats. The decline is predicted to continue at the same rate or slightly higher in the next 30-36 years (approximately three generations) ( $\mathrm{Vu}$ et al., 2008). In addition, grey-shanked douc is one of top 25 endangered primate species in the world (Schwitzer et al., 2014).

Few studies of grey-shanked douc langur have been so far conducted. These studies focused on investigating the presence (Ha, 2000; Nadler et al., 2003; Minh et al., 2005; Nguyen et al., 2010), or surveying for population size, density (Ha, 2003; 2004; 2007; Nguyen et al., 2007), and ecological characteristics such as food selection, and behavioural ecology (Ha, 2003; 2004; 2007; Nadler et al., 2003; Nguyen et al., 2012). These studies have provided useful information on the ecological characteristics of this species. Recently, new populations of GSDL are still being discovered (FFI, 2016), therefore, investigating the presence of the species in the areas that have not been surveyed before is necessary. Bett et al. (2012) modelled the distribution of the three species in the Pygathrix genus, however, vegetation and terrain-related variables were not used. Variables related to vegetation and terrain have been shown to be important in modelling the distribution of mammal species (Cork and Catling, 1996), especially for Pygathrix because these species only feeds on plants and move predominately in canopy. The terrain in the region where Pygrathrix has been recorded and surrounding region is remarkably diverse, the elevation range from $0 \mathrm{~m}$ asl up to $2600 \mathrm{~m}$ asl (Nadler and Brockman, 2014). More importantly, the vegetation also changes significantly with the elevation gradient as well as longitudinal and longitudinal gradients. Remarkably, vegetation is divided into two forest types, including dry forest and evergreen forest. This difference is believed to influence the distribution of the species. Bett et al. (2012) did not rank the site with varying suitability that is unusually needed for prioritizing sites for conservation activities. A distributional map that is modelled using climactic variables together with terrain and vegetation variables will be helpful in guiding the survey and conservation efforts for GSDL.

\section{Materials and methods}

\section{Study area}

The study area ranges from nearly $13^{\circ} \mathrm{N}$ to $16^{\circ} \mathrm{N}$, including parts of South Central Coastal region and Central Highland region of Vietnam. This area is separated from northern Vietnam by the Hai Van Pass and southern Vietnam by Ba-Da Rang river. The topography of this area is very complex. Mount Ngoc Linh on the northwestern Kon Tum Massif is the highest peak in the central of Vietnam $(2598 \mathrm{~m})$. The coastal lowlands and southern part have a drier, semi-arid climate with annual averaged rainfall below $750 \mathrm{~mm}$. The climate is less seasonal with averaged temperature ranging from $24{ }^{\circ} \mathrm{C}$ to $29^{\circ} \mathrm{C}$ throughout the year. The interior lowlands and foothills are wetter than the coastal area, with rainfalls from 1500-2000 mm per year. This area also has two distinct seasons including wet and dry seasons. The mountainous area of Annamite range is cooler and wetter than the lowland. Rainfall recorded at elevations above $1000 \mathrm{~m}$ is usually more than $2000 \mathrm{~mm}$ and increases with altitude. The vegetation and habitats of this area are also diverse. Under $800 \mathrm{~m}$, the evergreen broadleaf forest is 
dominated by tropical plant families such as Fagaceae and Magnoliaceae. As elevation increases the climate becomes cooler and wetter, mixed evergreen broadleaf forests and coniferous forests become dominated. Semi-evergreen forest and deciduous forest are dominating habitats in the south of Kon Tum Plateau (Sterling et al., 2006).

\section{Occurrence data}

We collected a total of 158 independent localities that recorded the occurrence of GSDL through previously published studies, including Tran and Hoang (2015); Ha (2000; 2003; 2004; 2007); Minh et al. (2005); Nadler (1997); Nadler et al. (2003); Nguyen et al. (2010) and aggregated data in Bett et al. (2012).

\section{Environmental variables}

To predict the appropriate distribution of GSDL, we collected and analyzed 25 environmental variables from different sources (Table 1). They were selected based on relationships between the variables and the ecological features of the species. These variables are often used in simulating the distribution of many species (Peterson et al., 2007; Kurmar and Stohlgren, 2009). Of the selected environmental variables, there were 19 climate variables and 3 topographical variables including altitude, slope, and slope direction. Vegetation-related variables included land cover, Normalized Difference Vegetation Index (NDVI), and percentage of tree cover. Climate variables consisting of 19 different map layers were downloaded from Woldclim (www.worldclim.com). These included 11 temperature variables and 8 precipitation related variables (Hijmans et al., 2005). Topographic map which was processed using the signal from The Shuttle Radar Topography Mission (SRTM) had $90 \mathrm{~m} \times 90 \mathrm{~m}$ resolution (downloaded from http://srtm.csi.cgiar.org). Slope and aspect data layer were calculated from the elevation map layer on ArcMap 10.1 (ESRI) software. The land cover map that was made using data from the MODIS image that was downloaded from http://landcover.usgs.gov/global_climatology.php (Broxton et al., 2014). The vegetation variable was categorized with assigned values ranging from 1 to 16 . The resolution of vegetation layer was $500 \times 500 \mathrm{~m}$. The normalized difference vegetation index (NDVI) for Asia was downloaded from https://earthexplorer.usgs.gov/ with $250 \times 250 \mathrm{~m}$ resolution. All NDVI layers of all months in 2013 were used to calculate the average NDVI layer of the year using ArcMap 10.1 software (ESRI). Percentage of tree cover is calculated based on canopy coverage. It is extracted from MODIS image with $500 \mathrm{~m} \times$ $500 \mathrm{~m}$ resolution (downloaded from http://www.iscgm.org/gm/glcnmo.html). In addition, the value 254 showed water surface and 255 meant no data area.

In order to eliminate highly correlated variables, data from 2000 randomly selected points in the region was exported to Excel for calculating the correlation coefficient. The Pearson correlation coefficient was used to calculate the correlation between pairs of variables. With pairs of variables having a coefficient of $|r|>0.85$ would retain only one variable for subsequent calculations. Finally, we selected 16 variables out of 25 variables for use in running the final model. The variables used are shown in Table 1.

\section{Prediction of distribution using MaxEnt}

Although there exist a variety of computer programs for modelling species distribution, in this study, the MaxEnt model was applied due to the following reasons: 1) MaxEnt outperforms other methods based on more accurate predictions; 2) The 


$$
-1279 \text { - }
$$

software is easy to use and suitable for small sample sizes (Peterson et al., 2007; Baldwin, 2009; Merow et al., 2013). In addition, MaxEnt is free software and can be downloaded from: http://biodiversityinformatics.amnh.org/open_source/maxent/ (Phillips et al., 2017).

Table 1. Environmental data variables were used in the model. (Bold variables were used in the final model prediction.)

\begin{tabular}{|c|c|c|}
\hline Variables & Source & Data type \\
\hline BIO1 = annual mean temperature & \multirow{19}{*}{ Worldclim } & \multirow{19}{*}{ Continuous } \\
\hline 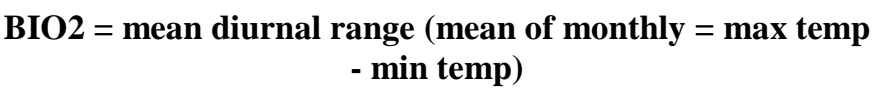 & & \\
\hline BIO3 = isothermality $(\mathrm{BIO} 2 / \mathrm{BIO} 7)(* 100)$ & & \\
\hline BIO4 = temperature seasonality (standard deviation $* 100)$ & & \\
\hline $\mathrm{BIO5}=$ max temperature of warmest month & & \\
\hline BIO6 $=$ min temperature of coldest month & & \\
\hline BIO7 = temperature annual range $(\mathrm{BIO5-BIO6)}$ & & \\
\hline $\mathrm{BIO} 8=$ mean temperature of wettest quarter & & \\
\hline $\mathrm{BIO}=$ mean temperature of driest quarter & & \\
\hline $\mathrm{BIO} 10=$ mean temperature of warmest quarter & & \\
\hline BIO11 = mean temperature of coldest quarter & & \\
\hline BIO12 = annual precipitation & & \\
\hline BIO13 $=$ precipitation of wettest month & & \\
\hline BIO14 = precipitation of driest month & & \\
\hline BIO15 = precipitation seasonality (coefficient of variation) & & \\
\hline $\mathrm{BIO} 16=$ precipitation of wettest quarter & & \\
\hline $\mathrm{BIO} 17=$ precipitation of driest quarter & & \\
\hline BIO18 = precipitation of warmest quarter & & \\
\hline BIO19 = precipitation of coldest quarter & & \\
\hline LcType = land cover & landcover.usgs.gov & Categorical \\
\hline TreeCover $=$ percent tree coverage & iscgm.org & Categorical \\
\hline NDVI & earthexplorer.usgs.gov & Continuous \\
\hline Elevation & srtm.csi.cgiar.org & Continuous \\
\hline Aspect & $\begin{array}{l}\text { Calculated from SRTM in } \\
\text { ArcMap }\end{array}$ & Continuous \\
\hline Slope $(\%)$ & $\begin{array}{c}\text { Calculated from SRTM in } \\
\text { ArcMap }\end{array}$ & Continuous \\
\hline
\end{tabular}

All data layers of the environmental variables were converted to raster and resampled to a resolution of $90 \times 90 \mathrm{~m}$. Data was then transformed to ASCII data (*.asc) using ArcMap 10.1 (ESRI) 
MaxEnt is the software that uses predictive methods to simulate the potential distribution of species from existing information (Phillips et al., 2006). Species occurrence data is used as input (called occurrence data), along with the use of environmental condition variables (such as temperature, rainfall, etc.) to interpolate for each grid cell. At present, the model is very popular for ecological niche modelling (distribution) of species. Several studies have used MaxEnt for distribution modelling of mammal species (Syfert et al., 2014) and (Nazeri et al., 2012). Particularly, the model have also been used to predict the distribution of primate species, for example: Hooclock gibbon (Sarma et al., 2015), Loris species in the genus Nycticebus (Thorn et al., 2009), Loris family (Kumara et al., 2009), and Pygathrix genus (Bett et al., 2012).

In this study, the following indexes were used: percentage of random sample to test $=$ $20 \%$, regularization multiplier $=0.2$, maximum iteration $=1000$, convergence threshold $=0.001$, maximum number of background points $=10,000$. These values have also been widely used in other studies (Nazeri et al., 2012; Sarma et al., 2015; Onojeghuo et al., 2015). Of 158 presence data points, 127 points were used as a training sample, and 31 points as reference data for validation.

The area under the response curve (AUC), with values ranging from 0 to 1 was used under application of the Receiver Operator Characteristic model (ROC) to determine model suitability (Phillips, 2006; Nazeri et al., 2012). In this context, AUC values > 0.75 (larger values meaning higher model suitability) allowed usage of the model for species distribution (Elith, 2000; Nazeri et al., 2015). When the AUC = 1, the predictive ability of the model is considered perfect. If the AUC $<0.5$, the model does not have the ability to predict (Phillips, 2006; Bett et al., 2012).

The background points chosen can strongly affect model outcome because of the geographic extent of any MaxEnt model. In this study, to avoid overestimating a lack of niche overlap we selected the study area encompassed the entire Indochinese peninsula. Running model in this entire area allowed us to determine the other suitable areas of $P$. cinerea extended beyond the current range in Central of Vietnam.

In order to assess variable importance, the Jacknife method (Pearson et al., 2007) was applied, where MaxEnt eliminated unsuitable variables, followed by model creation based upon the remaining suitable variables. Therewith, influences of model variables upon the general species model is shown (Phillips, 2006).

MaxEnt generated a map layer showing levels of suitability to GSDL with value ranging from 0 to 1 for each pixel, whereas greater pixel values represented higher prediction suitability. The files were generated in ASCII (*.asc) format and converted into raster format (*.tif) with ArcMap 10.1. In this study, the value of "equal training sensitivity and specificity" was used to classify suitable $(>0.2)$ and unsuitable areas $(0-$ $0.2)$. Then, suitable habitats were divided into 4 categories: Very high potential $(>0.8)$, High potential (0.6-0.8), Medium potential (0.4-0.6), Low potential (0.2-0.4).

\section{Results}

Discrimination capacity of the model ranged at $\mathrm{AUC}_{\text {train }}=0.987$ and $\mathrm{AUC}_{\text {test }}=$ 0.987 . Total area with high suitability was $367.7 \mathrm{~km}^{2}$ and low suitability about 7067.7 $\mathrm{km}^{2}$ (Figs. 2 and 3).

Potential distribution area as well as contribution of each environmental variable (temp; precip, etc) were modeled. The biggest contribution (27.7\%) resulted from precipitation of the driest month (bio14) followed by temperature annual range (bio7) 
(18.3\%). Temperature seasonality (bio4) and land cover (LCtype) ranged at $10.7 \%$ and 9.7\%, respectively (Table 2). Percentage contributions of Bio 1, Bio19, slope, NDVI, and aspect were small $(<1.0 \%)$.

Table 2. Analysis of variable contribution

\begin{tabular}{c|c|c|c|c|c}
\hline No & Variable & $\begin{array}{c}\text { Percentage } \\
\text { contribution (\%) }\end{array}$ & No & Variable & $\begin{array}{c}\text { Percentage } \\
\text { contribution (\%) }\end{array}$ \\
\hline 1 & Bio14 & 27.7 & 9 & Bio18 & 3.6 \\
\hline 2 & Bio7 & 18.3 & 10 & TreeCover & 2.7 \\
\hline 3 & Bio4 & 10.7 & 11 & Bio2 & 1.4 \\
\hline 4 & LcType & 9.7 & 12 & Bio1 & 0.6 \\
\hline 5 & Bio3 & 8.6 & 13 & Slope & 0.1 \\
\hline 6 & Bio15 & 6.1 & 14 & Bio19 & 0.1 \\
\hline 7 & Bio12 & 6.0 & 15 & NDVI & 0.1 \\
\hline 8 & Elevation & 4.2 & 16 & Aspect & 0 \\
\hline
\end{tabular}

The suitability of each variable for distribution areas of GSDL is shown in response curves (Appendix 1). For climatic variables, the results show that the potential distribution of GSDL concentrates in the areas where precipitation in the driest month ranges from 30 to $35 \mathrm{~mm}$ and annual rainfall from 2000 to $2300 \mathrm{~mm}$. The difference between the hottest month and the coldest month is best suited at around $16^{\circ} \mathrm{C}$ and average annual temperature at $19-24{ }^{\circ} \mathrm{C}$. Regarding vegetation it was found that GSDL preferred evergreen broadleaf forest (LCtype 2) over any other forest types. Suitable topographic elevations for GSDL ranged at [500,1400] $\mathrm{m}$ asl. Areas most suitable in this regard ranged at $[1000,1400] \mathrm{m}$ asl.

The Jackknife test in MaxEnt model shows that precipitation of driest month (bio14) and temperature annual range (bio7) are the most important variables if they are simulated in isolation to other variables. Omitting of annual precipitation (bio 12) and percentage of tree cover (TreeCover) resulted in reduced gain level of the model (Appendix 2).

\section{Discussion}

The map in Figure 2 graphically shows the expansion of suitable distribution area of GSDL ranging from 14 to $16^{\circ}$ North. The potential distribution lies within the boundaries of 5 provinces including Quang Nam, Quang Ngai, Kon Tum, Gia Lai and Binh Dinh. This modelling result fits the known distribution of the species (Ha, 2000; 2004; Nadler et al., 2003; Nguyen et al., 2010; Nadler and Brockman, 2014) and aligns with IUCN's distribution map, which indicates the models reliability. Our finding is also consistent with the previous study of Bett et al. (2012). However, Bett et al. (2012) only used climate-related variables. In our study, the vegetation-related variables (land cover, NDVI, and percentage of tree cover) and topographic variables (elevation, aspect, and slope) were added. In fact, these variables affect the predicted range of the species, thus increasing model precision through presence of more variables (Wilson et al., 2013). Therefore, potential distribution modelled for GSDL is narrowed down and becomes more fragmented. 
The model is divided into areas of varying suitability degrees, with suitable area for GSDL being mainly concentrated in the intersectional area between the south central coast and central highland and in the eastern and southern slope of Kon Tum Mountain (Fig. 2). These areas are wetter and receive more rain than western parts (Sterling et al., 2006). In addition, they still remain good natural broad-leaved forest habitats. Areas of highest suitability are mainly concentrated in the borders of Quang Ngai (Ba To district), Kon Tum (Kon Plong district), Binh Dinh (An Lao district) and Gia Lai (K 'Bang district) provinces; and in Kon Ka Kinh National Park, Kon Cha Rang Nature Reserve, An Toan Nature Reserve. Other high suitable areas lie among Nam Tra My, Bac Tra My, Hiep Duc, Phuoc Son, and Nam Giang districts of Quang Nam province. Thereby, the suitable areas for GSDL are mainly concentrated in the eastern and southern slope of Kon Tum Mountain.

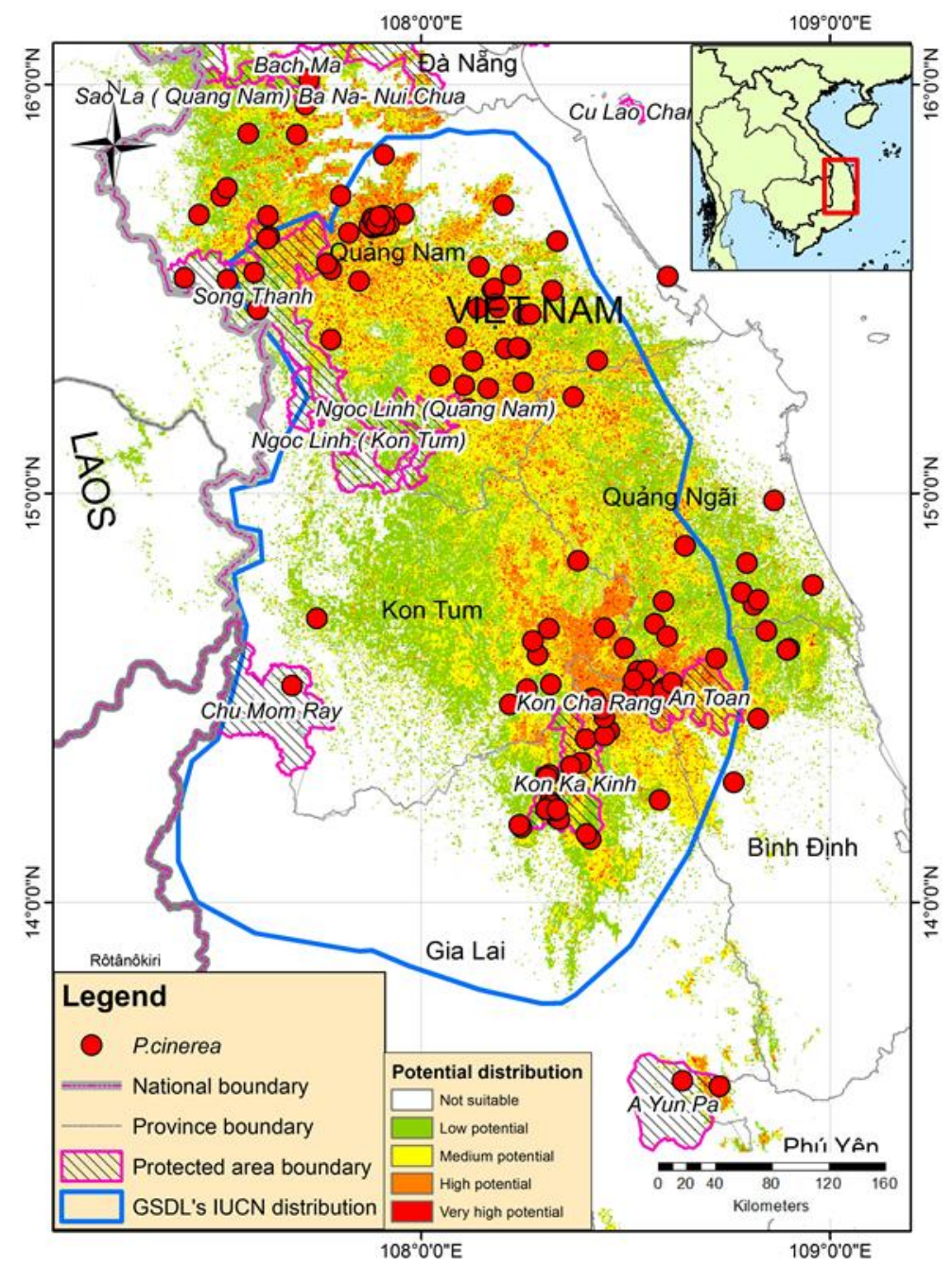

Figure 2. Prediction of areas potentially suitable for distribution of P. cinerea within protected area as well as occurrence data (red dots)

The total suitable area for GSDL at $16,680.52 \mathrm{~km}^{2}$. The low suitable areas account for about $42 \%$ of the total area. Of this, area with medium, high and very high suitability account for 37\%; $19 \%$ and $2 \%$ respectively (Fig. 3). The total area of 
GSDL's distribution within the boundaries of existing protected area system only ranges at $1680.37 \mathrm{~km}^{2}$ (about $10 \%$ of the total suitable area as the model predicted). Therefore, the current network of Vietnam's protected area occupies a small part of suitable habitat of GSDL, especially regarding areas of high and very high suitability. This result also indicates that more survey efforts to further to the north of the current distribution range of GSDL need to be considered for discovering new populations. The establishment of new protected areas for the conservation of wildlife and habitat protection is very important and urgent.

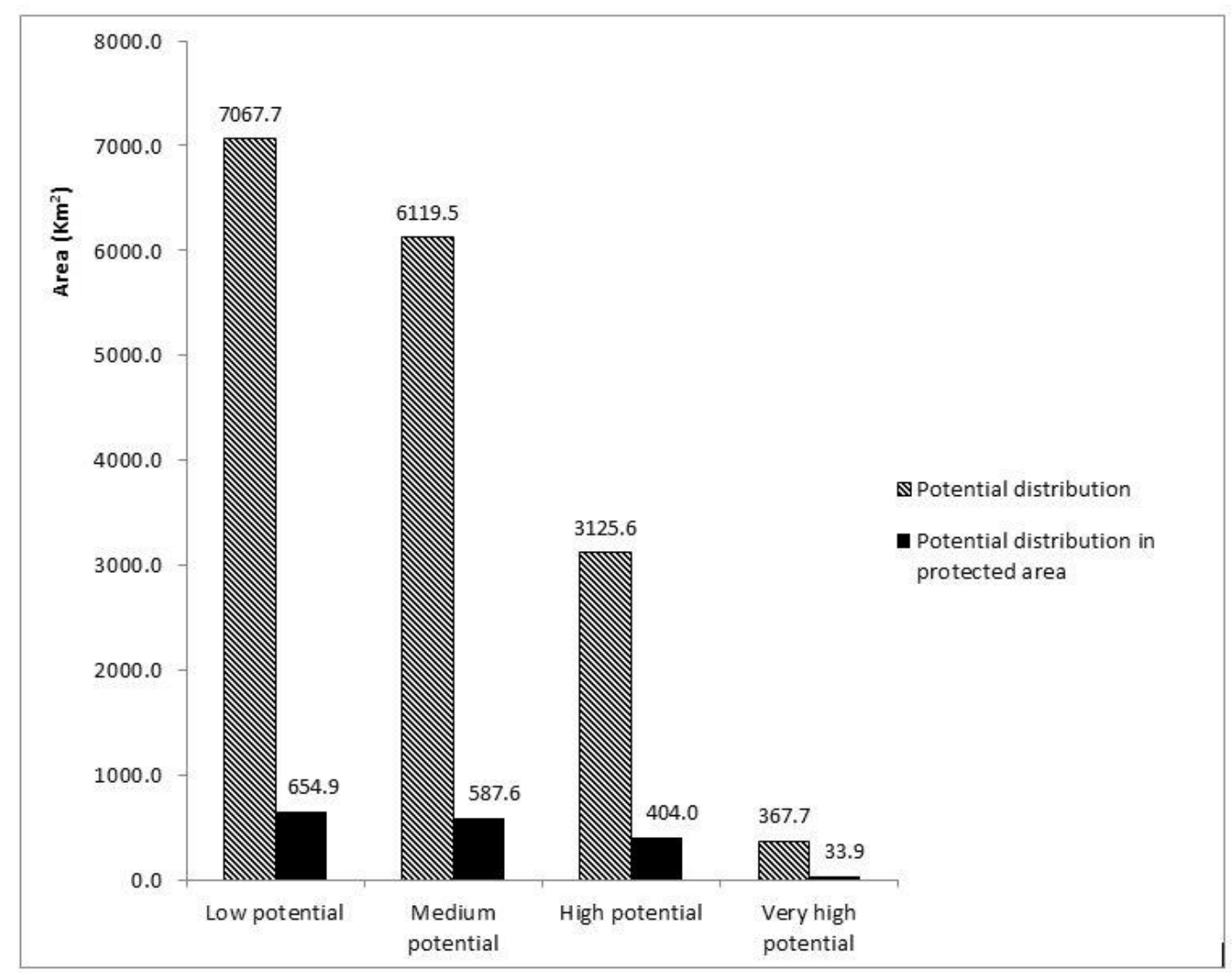

Figure 3. Potential distribution area of GSDL with low, medium, high, and very high suitability

By now, many species are threatened with extinction and face habitat loss. Habitat loss and a number of the individuals remaining are two greatest concerns for species conservation (Nazeri et al., 2012). In the case of rare primate species like GSDL, the greatest threats are habitat loss and hunting (Vu et al., 2008; Nguyen et al., 2012). The GSDL's potential distribution which is not included in the existing protected areas can cause severe impacts to the species population in the future. However, the establishments of protected areas only proceeds with long-term the national planning, which might interfere with economic development. Conservation outside the protected areas is critically important for GSDL.

The potential distribution area of GSDL is not much found within the existing protected areas but coincides with many proposed biodiversity corridors. For example, the area between Kon Ka Kinh National Park and Kon Cha Rang Nature Reserve is highly suitable for GSDL. It lies within the proposed corridor connecting Kon Ka 
Kinh NP and Kon Cha Rang Nature Reserve covering an area of about 108,607 $\mathrm{km}^{2}$. The objective of this corridor is to support and manage the biodiversity of the adjunction area (Breese, 2009). The area also coincides with a biodiversity corridor for adaptation and mitigation of climate change proposed by Vu (2014) with a length of about $20 \mathrm{~km}$ covering an area of about $95,116 \mathrm{~km}^{2}$. In addition, potential distribution areas of GSDL are also located in many other proposed biodiversity corridors such as Kon Cha Rang-Ngoc Linh, Ngoc Linh-Ngoc Linh, Ngoc Linh-Song Thanh, and Song Thanh-Sao La. These areas are quite large. Most of them are natural forest which is similar to the habitats found in protected forests. Therefore, the feasibility for establishment of biodiversity corridor is very high ( $\mathrm{Vu}, 2014)$. Biodiversity corridor establishment is urgently needed to improve the protection of GSDL throughout its entire distribution range.

Modelling of GSDL's potential distribution area has been applied based on ecological factors including climate, topography, and vegetation related variables in connection with occurrence data. In particular, environmental factors have a complex impact on the distribution of primates (Kamilar, 2009). Previous studies have also shown that the distribution of animals is highly dependent on the environment (Zonneveld et al., 2009) and that abiotic factors have different effects on the distribution of primates at different regions (Vidal-Garcia and Serio-Silva, 2011). Furthermore, climate biology features are also thought to affect the distribution of species in Pygathrix ssp. (Bett et al., 2012). The use of climate variables is an effective way of identifying geographical distributions of species (Sarmar et al., 2015). In the predictive distribution model of GSDL, precipitation of the driest month (bio14) has the highest effect of all parameters. This is in line with the findings of (Bett et al., 2012). In the South Central and Central Highland regions of Vietnam, climate features vary immensely. Differences in climatic conditions are due to a large variation in altitude, surrounding terrain and ridge direction (Sterling et al., 2006). In particular, a high mountain present between Da Nang city and Thua Thien Hue province creates the climatic difference between South-Central Coast and the Northern Central Coast regions which might be a major barrier for further expansion of GSDL to the North.

The high level of impact from climate variables within the model is a hint for future impacts of climate change on GSDL populations, potentially causing distribution shifts northward shifts distribution, or in areas of higher altitude. Influence upon the future distribution can occur eather in trends or shrinks (Root and Schneider, 2002). Therefore, more in-depth studies on the future impacts of climate change on species distribution are necessary. In addition to direct effects, climate change might indirectly affect the distribution of GSDL by influencing growth and distribution of flora consumed by the animals (Vidal-Garcia and Serio Silva, 2011; Sarma et al., 2015). The indirect effects of climatic factors might be critical as the species do predominately feeds on plants like GSDL. Another our study showed that the distribution of grey-shanked douc langur was predicted to decrease dramatically under the effects of climate change. Furthermore, the projections indicate that a larger suitable area will be disappeared, particularly high and very high suitable areas (Tran et al., 2018).

The influence of vegetation-related variables (land cover, percentage of tree cover, NDVI) within the model is not negligible. The predicted distribution shows that GSDL tend to be distributed in the evergreen broadleaved forest more than in any other forest types. Distribution is mainly limited to areas with percentage of tree cover of $60 \%$ or higher. This result is consistent with previously published studies on the ecology of 
GSDL (Ha, 2004; 2009; Nadler, 2014). GSDL prefer forest with high dense canopy cover and complex vertical structures that provides many types of fruits and seeds for feeding (Ha, 2009; Nguyen et al., 2012).

The potential distribution map of GSDL will be an important basis for the implementation of conservation programs for the species in the Central Highland and South Central Coast. Priority should be given to Kon Ka Kinh, Kon Cha Rang, and An Toan Nature Reserves, as well as the northern part of Song Thanh Nature Reserve because much of highly suitable area lies within these protected areas. Conservation outside the protected areas is also very important for GSDL because both modelling and field surveys have found the habitat outside the protected areas hold significant populations. Additionally, more surveying efforts should also be given to the area on the northern part of the distribution range and along the border between Kon Tum, Quang Nam, and Quang Ngai provinces.

\section{Conclusion}

The projection of MaxEnt model shows that the suitable area for GSDL is approximately from $14^{\circ} \mathrm{N}-16^{\circ} \mathrm{N}$. It lies within the boundaries of 5 provinces including Quang Nam, Quang Ngai, Kon Tum, Gia Lai and Binh Dinh. The precipitation of driest month (bio14) had the highest impact with $27.7 \%$. Then, the temperature annual range (bio7) was the second one with $18.3 \%$. The total suitable area of GSDL is $16,680.52 \mathrm{~km}^{2}$. The least suitable area accounts for about $42 \%$ of the total area. The area of medium suitability is about $37 \%$. The areas of high and very high suitability account for $19 \%$, and $2 \%$, respectively. The potential distribution area of the species is not much found in the existing protected areas. Priorities for conservation and survey efforts should be given to the forested areas in Quang Ngai (Ba To district), Kon Tum (Kon Plong district), Binh Dinh (An Lao district) and Gia Lai (K 'Bang district) provinces; and in Kon Ka Kinh National Park, Kon Cha Rang Nature Reserve, An Toan Nature Reserve. Another important areas lies among Nam Tra My, Bac Tra My, Hiep Duc, Phuoc Son, and Nam Giang districts of Quang Nam province. Conservation efforts should also be prioritized for areas beyond the boundary of protected areas, especially for areas that have been proposed as biodiversity corridor. In the next studies, we need to collect more occurrence data of GSDL in the field. In addition, we should add environmental variable such as the impacts of human or road systems in the study area to run the model. It allows MaxEnt model to increase the accuracy of the distribution. Furthermore, we should implement the deep studies about the impact of climate change on the distribution of GSDL by using the climate change scenarios in the future.

Acknowledgements. We are grateful to Ms. Pham Thi Nhung, Ms. Nguyen Thi Huyen Chung and Ms. Tran Thi Phuong Hoa (Vietnam National University of Forestry) for supporting the data collection.

\section{REFERENCES}

[1] Baldwin, R. A. (2009): Use of maximum entropy modeling in wildlife research. Entropy 11: 854-866.

[2] Bett, N. N., Blair, M. E., Sterling, E. J. (2012): Ecological niche conservatism in Doucs (Genus Pygathrix). - Int J Primatol 33: 972-988. 
[3] Breese, J. (2009): Making the Link: The Connection and Sustainable Management of Kon Ka Kinh National Park and Kon Chu Rang Natural Reserves. Final Report. - UNDP, Hanoi, Vietnam.

[4] Broxton, P. D., Zeng, X., Sulla-Menashe, D., Troch, P. A. (2014): A global land cover climatology using MODIS data. - J Appl Meteor Climatol 53: 1593 -1605. doi: http://dx.doi.org/10.1175/JAMC-D-13-0270.1.

[5] Cork, S. J., Catling, P. C. (1996): Modelling distributions of arboreal and grounddwelling mammals in relation to climate, nutrients, plant chemical defenses and vegetation structure in the eucalypt forests of south eastern Australia. - Forest Ecol Manag 85: 163-175.

[6] Elith, J. (2000): Quantitative Methods for Modeling Species Habitat: Comparative Performance and an Application to Australian Plants. - In: Ferson, S., Burgman, M. (eds.) Quantitative Methods for Conservation Biology. Springer, New York.

[7] FFI (2016): Vietnamese primatologists discover 500 grey-shanked douc langurs. http://vietnamnews.vn/society/283188/vietnamese-primatologists-discover-500-grey-

shanked-douc langurs.html\#74IQzgohrb3y68Yy.99. Accessed 8 May 2017.

[8] Franklin, J., Miller, J. A. (2009): Mapping Species Distributions - Spatial Inference and Prediction. - Cambridge University Press, New York.

[9] Ha, T. L. (2000): Records of Grey-shanked Douc Langur (Pygathrix cinerea) in the Central Highlands of Vietnam. Report. - Frankfurt Zoological Society-Vietnam Primate Conservation Programme. Frankfurt Zoological Society, Hanoi.

[10] Ha, T. L. (2003): A preliminary Survey of Distribution and Population of Grey-Shanked Douc Monkeys (Pygathrix cinerea) in Vietnam. - Oxford Brookes University, Oxford.

[11] Ha, T. L. (2004): Distribution and Status of the Grey-Shanked Douc (Pygathrix cinerea) in Vietnam. - In: Nadler T, Streicher U., Ha, T. L. (eds.) Conservation of Primates in Vietnam. Frankfurt Zoological Society, Hanoi.

[12] Ha, T. L. (2007): Distribution, population and conservation status of the grey-shanked douc (Pygathrix cinerea) in Gia Lai Province, Central Highlands of Vietnam. Vietnamese J Primatol 1: 55-60.

[13] Hijmans, R. J., Cameron, S. E., Parra, J. L., Jones, P. G., Jarvis, A. (2005): Very high resolution interpolated climate surfaces for global land areas. - Int J Climatol 25: 19651978.

[14] Hirzel, A. H., Hausser, J., Chessel, D., Perrin, N. (2002): Ecological niche factor analysis: how to compute habitat-suitability maps without absence data. - Ecology 87: 2027-2036.

[15] Kamilar, J. M. (2009): Environmental and geographic correlates of the taxonomic structure of primate communities. - Am J Phys Anthropol 139: 382-393.

[16] Kumar, S., Stohlgren, T. J. (2009): Maxent modeling for predicting suitable habitat for threatened and endangered tree Canacomyrica monticola in New Caledonia. - J Ecol Nat Environ 1: 094-098.

[17] Kumara, H. N., Irfan-Ullah, M., Kumar, S. (2009): Mapping potential distribution of slender loris subspecies in peninsular India. - Endanger Species Res 7: 29-38.

[18] Merow, C., Smith, M. J., Silander, J. A. Jr. (2013): A practical guide to MaxEnt for modeling species' distributions: what it does, and why inputs and settings matter. Ecography 36: 1058-1069. doi: 10.1111/j.1600-0587.2013.07872.x.

[19] Minh, H., Khanh, T. V., Thuong, H. V., Long, B. (2005): Primate Conservation in Quang Nam Province, Central Vietnam. - WWF Indochina and Quang Nam Forest Protection Department, Vietnam.

[20] Ministry of Science and Technology and Vietnam Academy of Science and Technology (2007): Vietnam's Red Data Book, Part I. - Animals, Natural Science and Technology Publishing Company, Hanoi.

[21] Nadler, T. (1997): A new subspecies of douc langur, Pygathrix nemaeus cinereus ssp. nov. - Zoologischer Garten (NF) 67: 165-176. 
[22] Nadler, T. (2010): Status of Vietnamese Primates - Complements and Revisions. - In: Nadler, T., Rawson, B. M., Van, N. T. (eds.) Conservation of Primates in Indochina. Frankfurt Zoological Society and Conservation International, Hanoi.

[23] Nadler, T., Brockman, D. (2014): Primates of Vietnam. - Endangered Primate Rescue Center, Cuc Phuong National Park, Ninh Binh.

[24] Nadler, T., Momberg, F., Dang, N. X., Lormee, N. (2003): Vietnam Primate Conservation Status Review 2002. - Fauna and Flora International and Frankfurt Zoological Society, Hanoi.

[25] Nazeri, M., Jusoff, K., Madani, N., Mahmud, A. R., Bahman, A. R., Kumar, L. (2012): Predictive Modeling and Mapping of Malayan Sun Bear (Helarctos malayanus) Distribution Using Maximum Entropy. - PLoS ONE 7: e8104. doi:10.1371/journal.pone.0048104.

[26] Nguyen, T. T., Le, V. K., Le, K. Q. (2010): New data on the distribution of grey-shanked douc langurs (Pygathrix cinerea) in Quang Ngai Province, Vietnam. - In: Nadler, T., Rawson, B. M., Van, N. T. (eds.) Conservation of Primates in Indochina. Frankfurt Zoological Society and Conservation International, Hanoi.

[27] Nguyen, T. T., Ha, T. L., Bui, V. T., Tran, H. V., Nguyen, A. T. (2012): The feeding behavior and phytochemical food content of grey-shanked douc langur (Pygathrix cinerea) at Kon Ka Kinh National Park, Vietnam. - Vietnamese J Primatol 2: 25-35.

[28] Onojeghuo, A. O., Blackburn, A. G., Okeke, F., Onojeghuo, A. R. (2015): Habitat Suitability Modeling of Endangered Primates in Nigeria: Integrating Satellite Remote Sensing and Spatial Modeling Techniques. - Journal of Geoscience and Environment Protection 3: 23-38.

[29] Pearson, R. G., Raxworthy, C. J., Nakamura, M., Peterson, A. T. (2007): Predicting species' distributions from small numbers of occurrence records: A test case using cryptic geckos in Madagascar. - J Biogeogr 34: 102-117.

[30] Peterson, A. T., Papes, M., Eaton, M. (2007): Transferability and model evolution in ecological niche modeling: a comparison of GARP and MAXENT. - Ecography 30: 550560.

[31] Phillips, S. J. (2006): A Brief Tutorial on Maxent. - AT\&T Research, Florham Park, New Jersey. http://www.cs.princeton.edu/ schapire/maxent/tutorial/-tutorial.doc. Accessed 28 December 2016.

[32] Phillips, S. J., Anderson, R. P., Schapire, R. E. (2006): Maximum entropy modeling of species geographic distributions. - Ecol Model 190: 231-259.

[33] Phillips, S. J., Dudík, M., Schapire, R. E. (2017): [Internet] Maxent software for modeling species niches and distributions (Version 3.4.1). http://biodiversityinformatics.amnh.org/open_source/maxent/. Accessed 4 October 2017.

[34] Raxworthy, C. J., Ingram, C. M., Rabibisoa, N., Pearson, R. G. (2007): Application of ecological niche modeling for species delimitation: A review and empirical evaluation suing day Geckos (Phelsuma) from Madagascar. - Syst Biol 56: 907-923. doi:10.1080/10635150701775111.

[35] Roos, C., Nadler, T. (2001): Molecular evolution of the Douc Langurs. - Zool Garten N F 7: 11-6.

[36] Root, T. L., Schneider, S. H. (2002): Climate Change: Overview and Implications for Wildlife. - In: Schneider, S. H., Root, T. L. (eds.) Wildlife Responses to Climate Change: North American Case Studies. Island Press, Washington D. C.

[37] Sarma, K., Kumar, A., Krishna, M., Medhi, M., Tripathi, O. P. (2015): Predicting suitable habitats for the Vulnerable Eastern Hooclock Gibbon Hoolock leuconedys, in India using the MaxEnt model. - Folia Primatol 86: 387-397. doi: 10.1159/000381952.

[38] Schwitzer, C., Mittermeier, R. A., Rylands, A. B., Taylor, L. A., Chiozza, F., Williamson, E. A., Wallis, J., Clark, F. E. (eds.) (2014): Primates in Peril: The World's 25 Most Endangered Primates 2012-2014. - IUCN SSC Primate Specialist Group, International 
Primatological Society, Conservation International, and Bristol Zoological Society, Arlington, VA.

[39] Sterling, E. J., Hurley, M. M., Le, M. D. (2006): A Natural History of Vietnam. - Yale University Express, New Haven.

[40] Syfert, M. M., Joppa, L., Smith, M. J., Coomes, D. A., Bachman, S. P., Brummitt, N. A. (2014): Using distribution models to inform IUCN Red List assessments. - Biol Conserv 177: $174-184$.

[41] Thorn, J. S., Nijman, V., Smith, D., Nekaris, K. A. I. (2009): Ecological niche modeling as a technique for assessing threats and setting conservation priorities for Asian slow lorises (Primates: Nycticebus). - Divers Distrib 15: 289-298.

[42] Tran, V. B., Hoang, M. D. (2015): First records of primate species of A Yun Pa proposed nature reserve. - Proceeding of the Sixth National Workshop on Ecology and Biological Resources, Hanoi, Vietnam.

[43] Tran, V. D, Tran, T. P. H., Ta, T. N., Vu, T. T. (2018): Assessing impact of future climate chage on the distribution of Gray-shanked douc (Pygathrix cinerea) using ecological niche modelling. - In press.

[44] Vidal-Garcia, F., Serio-Silva, J. C. (2011): Potential distribution of Mexican primates: Modeling the ecological niche with the maximum entropy algorithm. - Primates 52: 261270.

[45] Vu, N. T., Lippold, L., Nadler, T., Timmins, R. J. (2008): Pygathrix cinerea. - The IUCN Red List of Threatened Species 2008: e.T39827A10273229. http://dx.doi.org/10.2305/IUCN.UK.2008.RLTS.T39827A10273229.en. Accessed 27 December 2016.

[46] Vu, T. T. (2014): Proposing green corridors to conserve biodiversity of southern Vietnam in the context of climate change. - Journal of Forest and Environment 65: 24-31.

[47] Warren, D. L., Seifert, S. N. (2011): Ecological niche modeling in MaxEnt: the importance of model complexity and the performance of model selection criteria. - Ecol Appl 21: 335-342.

[48] Wilson, J. W., Sexton, J. O., Jobe, R. T., Haddad, N. M. (2013): The relative contribution of terrain, land cover, and vegetation structure indices to species distribution models. Biol Conserv 164: 170-176.

[49] Zonneveld, M. V., Koskela, J., Vinceti, B., Jarvis, A. (2009): Impact of climate change on the distribution of tropical pines in Southeast Asia. - Unasylva Journal 60: 24-29. 


$$
-1289 \text { - }
$$

\section{Appendix 1}

Variable response curves for the predictors of Pygathrix cinerea by the MaxEnt model
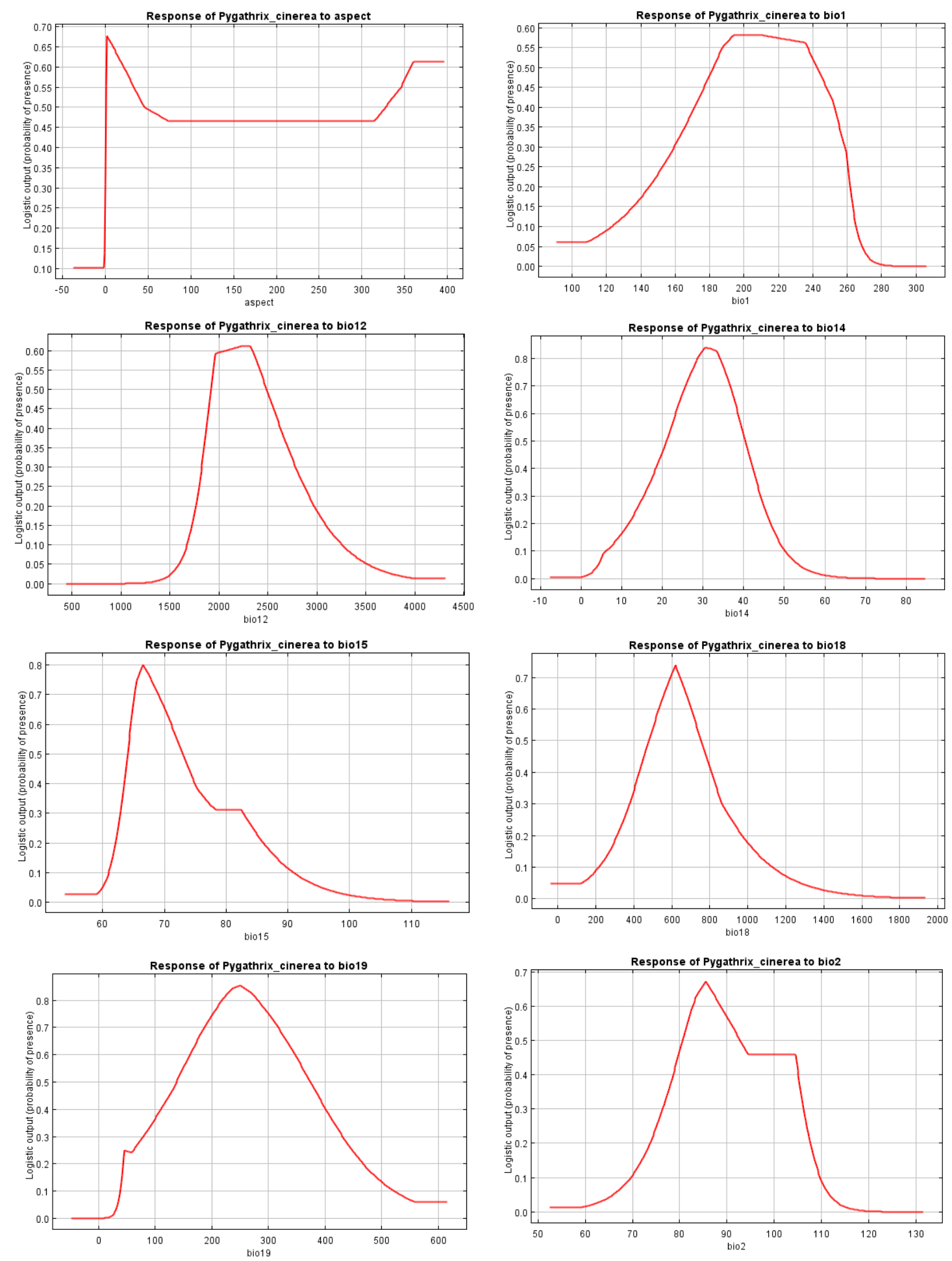

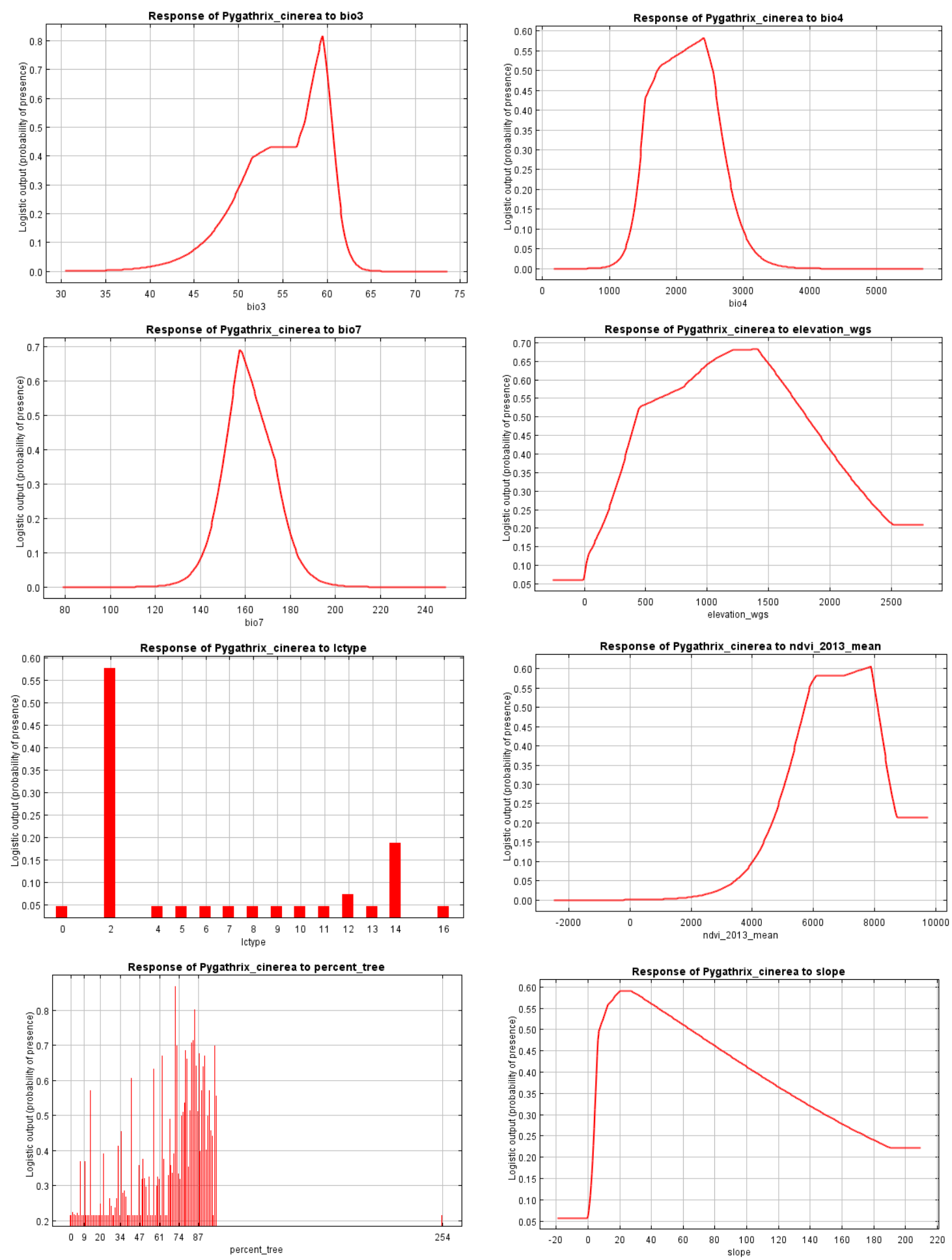


$$
\text { - } 1291 \text { - }
$$

\section{Appendix 2}

Results of jackknife test of relative variable importance of predictor variable for Pygathix cinerea

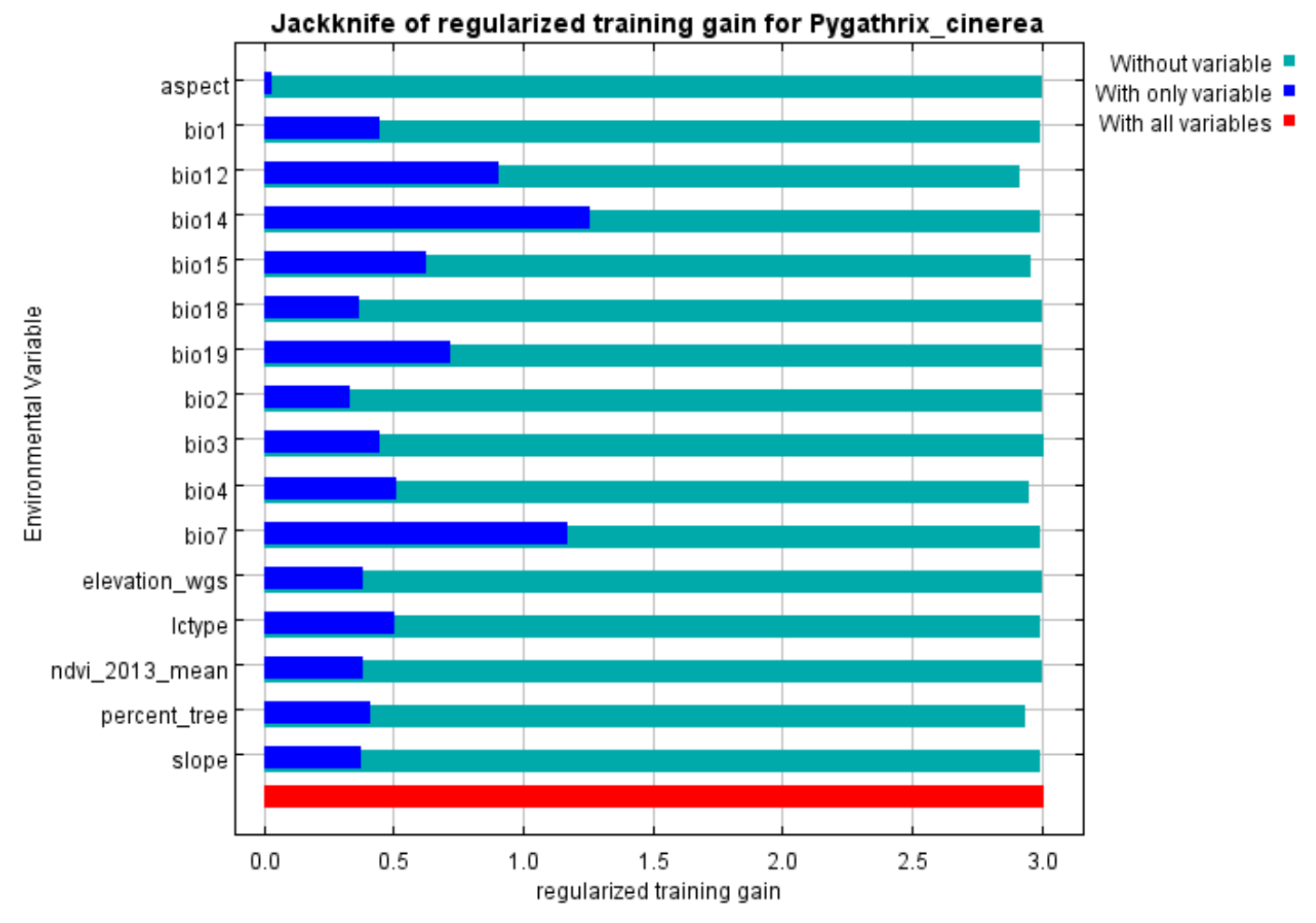

